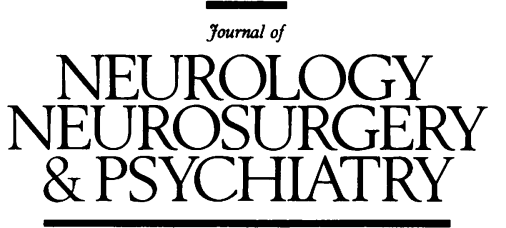

Editorial

\title{
Surveying multiple sclerosis in the United Kingdom
}

Making lists of those in whom the diagnosis of multiple sclerosis has already been made, or identifying persons with one particular feature of the disease, is not a difficult exercise and as a result the disease has been surveyed in many places and on many occasions. The usual reason has been to use temporal and geographical trends in morbidity and mortality to generate hypotheses for the cause. For this purpose, it is essential to know that the individual studies can reliably be compared so as not to base hypotheses for the aetiology of multiple sclerosis on shaky epidemiological foundations. Taken together, the conceptual yield from these epidemiological surveys has been poor given the effort that has gone into the enumeration of cases; many questions have been left unanswered and the results have proved tantalisingly vague in providing a detailed understanding of factors which determine the frequency and distribution of the disease.

Every student of the subject is taught that the epidemiology of multiple sclerosis shows a latitudinal gradient in frequency. ${ }^{1}$ Some commentators take the view that this reflects differences in exposure to an environmental trigger which is unevenly distributed. ${ }^{2}$ Others conclude that the gradient arises from the non-uniform distribution of susceptibility genes among different racial groups. ${ }^{3}$ Although it is interesting to interpret the epidemiology of multiple sclerosis through the social history of northern Europeans, ${ }^{4}$ the epidemiological sands of multiple sclerosis are shifting with the migrations of the peoples whose neurological disorders they seek to understand, making serial and comparative studies difficult to interpret. In the end, the race or place debate is of doubtful impact as ideas on polygenic and multifactorial disease leave plenty of room for proposing an interplay between genetic and environmental factors. ${ }^{5}$

The study of multiple sclerosis in the United Kingdom has been of special importance as the disease has at one time been more common in the north eastern corner of the British Isles than anywhere else in the world. In 1986 , the distribution of multiple sclerosis in the United Kingdom was reviewed in this fournal ${ }^{6}$ using published figures for prevalence, incidence, and mortality and confining the analysis of prevalence to definite or probable cases; we concluded then that a frequency gradient exists which correlates with a genetic cline marked by the HLA-DR2 susceptibility allele. Williams et $\mathrm{al}^{7}$ subsequently reanalysed mortality statistics, calculating annual age and sex specific figures standardised to death rates in the United Kingdom for 1974; they found less evidence for the north-south gradient and considered (on the basis of a fall in mortality) that the incidence of multiple sclerosis had been falling in Scotland. Mortality is adequate as a measure of disease frequency only when no distinction is made between death with and death from multiple sclerosis but Williams and colleagues considered only those with multiple sclerosis as the underlying cause of death and so underestimated absolute numbers by between $30 \%$ and $50 \%$. While confirming the general trend towards a reduction in death rates throughout the United Kingdom, they showed that this was more pronounced in Scotland (39\%) and Northern Ireland than in England and Wales (10\%) and highlighted the conspicuous reduction in mortality for Scots aged $>65$ years. Although the failure to show a correlation between temporal and geographical trends for mortality and prevalence invites the comment that the mortality returns used by Williams et $a l^{7}$ were too crude for useful analysis, we argue later in this review that the same criticism can be levied at figures for prevalence-traditionally considered the more robust statistic.

One of several concerns about each of these analyses has been the quality of the primary information and this led Swingler, Taylor, and Hall (RJ Swingler, personal communication) to compare statistics for multiple sclerosis based on entries for 3617890 people into the Value Added Medical Products (VAMP) system for storing general practice records in England and Wales, with the 527736 listed in the General Practice Administration System for Scotland (GPASS). The standardised prevalence ratio for England and Wales was 116 (95\% confidence intervals (95\% CIs) $112-120)$ and for Scotland it was 158 (95\% CI 147-170); in reducing the comparison between morbidity statistics for multiple sclerosis to a single rate each for Scotland and for England and Wales, the national difference in frequency (137 (95\% CI $126-148) \%$ more multiple sclerosis in Scotland) is demonstrated without undue emphasis on district or regional variations-often the result of demographic peculiarities such as the location of facilities for the young disabled.

Recent epidemiological studies confirm the high overall frequency of multiple sclerosis in the United Kingdom and, with notable exceptions, continue to show a temporal trend of increasing prevalence in each newly surveyed district; thus to the previously reported prevalences of $117 / 10^{5}$ in south east Wales, ${ }^{89} 115 / 10^{5}$ in the urban area of Sutton close to London, ${ }^{10} 99 / 10^{5}$ in Southampton, ${ }^{11}$ and $178 / 10^{5}$ in north east Scotland ${ }^{12}$ can be added figures of $130 / 10^{5}$ for south east Cambridgeshire ${ }^{13}$ and $153 / 10^{5}$ in rural Suffolk. ${ }^{14}$ This issue of the fournal contains reports of first surveys for the Mid-Downs and Brighton districts of Sussex in southern England ${ }^{15}\left(111 / 10^{5}\right)$ and for two Bailiwicks of the Channel Islands ${ }^{16}$ (Jersey-113/10 5 and Guernsey-87/105), which come within the administrative boundaries of the United Kingdom but, being 
70-100 miles south of the English mainland, are latitudinally comparable with western France (lying 10-30 miles to the west) and represent something of a genetic bouillabaisse by comparison with southern England.

In 1995, an overview of published surveys of multiple sclerosis in the British Isles seems to show three trends; a difference in frequency between the north east mainland and off-shore islands of Scotland compared with other parts of the United Kingdom; a steep rise in prevalence with repeated survey in all areas except some parts of north east Scotland; and, consequentially, a gradual levelling of the previously shown gradient in frequency.

This gradient was most apparent when the estimate for prevalence of multiple sclerosis had been serially updated in north east Scotland ${ }^{122-20}$ and in the Orkney islands, ${ }^{21-23}$ where by 1974 the figure for Orkney stood at $309 / 10^{5}$, and very few other parts of the United Kingdom had been surveyed. In their definitive study, Poskanzer and colleagues $^{23}$ searched archival material and concluded that the first example of disseminated sclerosis occurred in an Orcadian who died in 1898; a second case was reported 10 years later and thereafter the diagnosis became more common, coinciding with a general increase in awareness and the adoption of clinical criteria for the diagnosis in neighbouring parts of Scotland. Changes in disease frequency in the first few decades of the 20th century can reasonably be attributed to alterations in nosological fashion and this led Poskanzer to conclude that multiple sclerosis may have been no less frequent an illness in 19th century Orcadians, than it later became. Estimates of prevalence, however, carried out on four occasions showed a steady rise from $111 / 10^{5}$ in $1954^{21}$ to $309 / 10^{5}$ in $1974^{23}$ for Orkney, and from $134 / 10^{5}$ to $184 / 10^{5}$ in Shetland over the same period. ${ }^{21-23}$ Recognising that these changes did not necessarily reflect increased incidence, Poskanzer et al defined (as accurately as possible) the date of onset in 66 Orcadian and 53 Shetland cases incident between 1930 and 1969, and showed an average annual incidence of $2 \cdot 2 / 10^{5} /$ year for Orkney and $1 \cdot 6 / 10^{5} /$ year in Shetland with stable quinquennial rates over this period. ${ }^{23}$

Later, Cook and colleagues ${ }^{24}$ documented the annual incidence from 1941 to 1983 and suggested that there had been a steady reduction from 1964. Between 1941 and 1964,53 patients with probable multiple sclerosis were identified in a population of 500000 whereas only 12 patients developed the disease among the population of 320000 living on the islands between 1965 and 1982 . By 1983, the quoted prevalence had also fallen from $309 / 10^{5}$ in 1974 to $224 / 10^{5}$ (the figures were $257 / 10^{5}$ and $193 / 10^{5}$ for probable cases only, in 1974 and 1983 respectively). This reduction in frequency of multiple sclerosis apparent in north east Scotland is matched by epidemiological surveys from other regions that border the North Sea and several authors have argued that a change has occurred in environmental factors determining the frequency of multiple sclerosis in these places..$^{25-27}$ If these trends reflect a change in biological factors that determine the frequency of multiple sclerosis, this can only reasonably be attributed, as has been claimed, to a change in environmental conditions; population genetics shape the distribution of disease more slowly. Elsewhere the systematic increase in morbidity statistics for prevalence with time and gradual erosion of the latitudinal gradient probably result from a catching up effect of more recently surveyed areas with those areas that have been repeatedly studied over a longer period.

Poskanzer et al identified several factors which maximise the prevalence of multiple sclerosis surveyed serially and on islands; systematic depopulation of Orkney and Shetland by the young led to an older population after the $1960 \mathrm{~s}$, less at risk of developing multiple sclerosis; the opposite is the case for the rural survey from Suffolk where those aged $<35$ years are over-represented. ${ }^{14}$ Prevalence rising out of line with incidence was attributed by Poskanzer et $a^{23}$ to increased survival (from 26 to 40 years in Orkney and from 24 to 34 years in Shetland between 1954 and 1974); the change in prevalence also resulted from improved recognition; and the criteria for diagnosis had also been altered. Several of these factors have influenced the steady rise in prevalence with repeated survey seen in other parts of the United Kingdom. Despite the completion of contemporary surveys for several regions of England and Wales, however, comparisons are not made easy by inconsistent use of classification systems and inclusion criteria, and by the failure to standardise morbidity statistics for population structure, so that even now it is difficult to construct a comprehensive multipoint prevalence map of multiple sclerosis in the United Kingdom. A quick glance at published figures for prevalence is not sufficient; more detailed scrutiny of diagnostic criteria, inclusion or omission of suspected cases, quotation of confidence intervals, variable citation of crude and age adjusted figures, reworking of statistics for time of onset not diagnosis, ${ }^{28}$ and adjustment for a standardised population (but, if so, which one?) are all methodological variables which restrict epidemiological vision. One need look for confirmation no further than the tables of Rice-Oxley et al ${ }^{15}$ and Sharpe and colleagues ${ }^{16}$ quoting entirely different standardised prevalence ratios for multiple sclerosis in published studies relating to the British Isles (this Fournal; table 3, page 29; and table 2, page 24 respectively).

Until the mid-1980s, studies of multiple sclerosis in the United Kingdom used the system of classification suggested by Allison and Millar. ${ }^{29}$ Adopting the Poser criteria, ${ }^{30}$ which were introduced to take account of advances in the laboratory investigation of multiple sclerosis, does not materially affect estimates for the total number of prevalent cases or the standardised prevalence ratios based on this numerator. Differences arise, however, when surveys are restricted to the categories of definite and probable (Poser) and probable and early (Allison and Millar) cases as the proportion in the suspected (Poser) and possible (Allison and Millar) categories needing exclusion differs significantly between the two classifications. Allison and Millar categorised cases as probable (usually a remitting history and always with signs attributable to more than one lesion), early (remitting symptoms with no signs), and possible (progressive or static symptoms at a single site, and with no other identified cause). Laboratory investigations were not taken into account and indeed few were available at that time. The most widely cited version of the Poser criteria ${ }^{30}$ does not deal with suspected cases; these are assumed to be all those thought to have demyelinating disease but with neither clinical symptoms or signs, or laboratory evidence, for more than one lesion. Some surveys have used the Poser criteria but ignore features such as age at presentation and particular laboratory investigations. ${ }^{815}$ Both classification systems were first used in parallel for the initial survey of south Glamorgan. ${ }^{8}$

For all these reasons, it is not possible to compare the analysis of probable cases defined using the Allison and Millar classification that we performed in $1986^{6}$ with any of the more recent publications on multiple sclerosis. The full range of inconsistency that has contaminated the description of these morbidity statistics for the United 
Major contemporary United Kingdom multiple sclerosis prevalence studies (all figures per 100 000)

\begin{tabular}{|c|c|c|c|c|c|c|c|c|c|c|c|c|}
\hline \multirow[b]{2}{*}{ Study } & \multirow[b]{2}{*}{ Latitude } & \multirow[b]{2}{*}{ Year } & \multirow[b]{2}{*}{ Population } & \multirow[b]{2}{*}{ Cases (n) } & \multicolumn{8}{|c|}{ Allison and Millar } \\
\hline & & & & & All & $95 \% C I$ & $M S$ & $\operatorname{Pt} \mathrm{No}$ & $95 \% C I$ & Poss & Pt No & $95 \% C I$ \\
\hline Shetlands & 60 & 1954 & 18715 & 25 & 134 & $90-198$ & 118 & 22 & $77-179$ & 16 & 3 & $5-50$ \\
\hline Shetlands & 60 & 1962 & 17537 & 29 & 165 & $115-238$ & 120 & 21 & $78-184$ & 46 & 8 & $22-91$ \\
\hline Shetlands & 60 & 1970 & 17327 & 31 & 179 & $126-258$ & 133 & 23 & $88-200$ & 46 & 8 & 23-92 \\
\hline Shetlands & 60 & 1974 & 18445 & 34 & 184 & $132-258$ & 152 & 28 & $105-220$ & 33 & 6 & $15-73$ \\
\hline Orkneys & 59 & 1954 & 20746 & 23 & 111 & $74-167$ & 82 & 17 & $51-132$ & 29 & 6 & $13-65$ \\
\hline Orkneys & 59 & 1962 & 18531 & 33 & 178 & $127-250$ & 168 & 31 & $118-238$ & 11 & 2 & $3-43$ \\
\hline Orkneys & 59 & 1970 & 17077 & 40 & 234 & $172-319$ & 222 & 38 & $162-305$ & 12 & 2 & $3-47$ \\
\hline Orkneys & 59 & 1974 & 17462 & 54 & 309 & $237-404$ & 257 & 45 & $192-344$ & 51 & 9 & $27-99$ \\
\hline Orkneys & 59 & 1983 & 19182 & 46 & 240 & $180-320$ & 209 & 40 & $153-284$ & 31 & 6 & $14-70$ \\
\hline Aberdeen & 57 & 1970 & 440176 & 557 & 127 & $116-137$ & 105 & 464 & 96-115 & 21 & 93 & $17-26$ \\
\hline Aberdeen & 57 & 1973 & 440176 & 634 & 144 & $133-156$ & 117 & 517 & $108-128$ & 27 & 117 & $22-32$ \\
\hline Aberdeen & 57 & 1980 & 471000 & 839 & 178 & $166-191$ & 145 & 682 & $134-156$ & 33 & 157 & $29-39$ \\
\hline N Ireland & 55 & 1951 & 1370709 & 700 & 51 & $47-55$ & 41 & 555 & $37-44$ & 11 & 145 & $9-12$ \\
\hline N Ireland $\star \star \star$ & 55 & 1961 & 1425000 & 1146 & 80 & $76-85$ & 57 & 808 & $53-61$ & 24 & 338 & $21-26$ \\
\hline N Ireland & 55 & 1987 & 86500 & 119 & 138 & $115-165$ & 104 & 90 & $85-128$ & 34 & 29 & $23-48$ \\
\hline SE Wales & 52 & 1985 & 376718 & 441 & 117 & $107-129$ & 84 & 316 & $75-94$ & 33 & 125 & $28-40$ \\
\hline SE Wales & 52 & 1988 & 376718 & 453 & - & - & - & - & - & $\overline{0}$ & - & - \\
\hline Suffolk & 52 & 1988 & 31379 & 62 & 198 & $154-253$ & 185 & 58 & $143-240$ & 13 & 4 & $5-34$ \\
\hline Cambs & 52 & 1990 & 288410 & 374 & 130 & $117-144$ & 107 & 309 & 96-120 & 23 & 65 & $18-29$ \\
\hline Cambs & 52 & 1993 & 290700 & 441 & 152 & $138-167$ & 120 & 349 & $108-133$ & 32 & 92 & $26-39$ \\
\hline Sutton & 51 & 1985 & 170000 & 195 & 115 & $100-132$ & 104 & 176 & $89-120$ & 11 & 19 & $7-18$ \\
\hline Southampton & 51 & 1987 & 417000 & 411 & 99 & $90-109$ & 92 & 384 & $83-102$ & 7 & 28 & $5-10$ \\
\hline Sussex & 51 & 1991 & 596594 & 810 & 136 & $127-145$ & 120 & 718 & $108-133$ & 32 & 92 & 26-39 \\
\hline Jersey & 49 & 1991 & 84082 & 95 & 113 & $92-138$ & 106 & 89 & $86-130$ & 7 & 6 & $5-19$ \\
\hline Guernsey & 49 & 1991 & 61164 & 53 & 87 & $66-113$ & 74 & 45 & 55- 99 & 13 & 8 & $7-26$ \\
\hline
\end{tabular}

$\star \star$ Standard population. For Allison and Millar; All = probable early and possible cases; MS = probable and early cases; Poss = possible cases only. For Poser; All

= definite, probable, and suspected cases; $M S$ = definite and probable cases; Susp = suspected cases only.

Kingdom (and the problems are no less elsewhere) is shown in the table, which lists major surveys reporting the prevalence of multiple sclerosis in parts of the United Kingdom reported since the 1950 s, and the figure, which plots the most recent estimate for prevalence at each location against latitude. The 1961 study from Northern Ireland is included as this forms the yardstick from which standardised prevalence ratios have, in most cases, since been calculated. ${ }^{31}$ This figure was updated in $1987 . .^{32}$ Some other studies performed in the United Kingdom over this period cannot be worked into the overall analysis of morbidity statistics for multiple sclerosis and are not included as they are based on small numerators and denominators, used neither the Allison and Millar nor the Poser criteria, or were restricted to one particular racial group. These include surveys of the Western Isles in $1954^{17}$ and $1979,{ }^{33}$ Northumberland and Durham, ${ }^{34}$ Carlisle, ${ }^{35}$ Yorkshire, ${ }^{36}$ Cornwall in $1950^{37}$ and $1958,{ }^{38}$ and immigrants from the new Commonwealth countries. ${ }^{39}$ Whereas we are confident that our reporting of these figures is accurate, assiduous readers will notice some differences from the primary literature. These mainly affect confidence intervals-an important and often omitted feature of prevalence studies. The most appropriate method of calculation varies depending on the size of the numerator; for the range represented in these surveys, we calculated confidence intervals as:

Upper limit $=\left(\right.$ numerator/denominator measured in $\left.10^{5}\right) \times \mathrm{Z}$
Lower limit $=\left(\right.$ numerator/denominator measured in $\left.10^{5}\right) / \mathrm{Z}$
where $\mathrm{Z}$ is given as: $\exp (1.96 \times$ [square root of $1 /$ numerator] $)$

In some surveys, enough information is given to allow calculation of rates which compare more closely to figures quoted for other regions. For example, the published prevalence for Suffolk ${ }^{14}$ is $153 / 10^{5}$ (confidence intervals not given) but this refers only to probable cases and excludes both the early and possible categories of Allison and Millar; we have derived a figure of $198 / 10^{5}$ (95\% CI 154-253) for all cases of multiple sclerosis, as shown. The figure for Southampton shows an internal

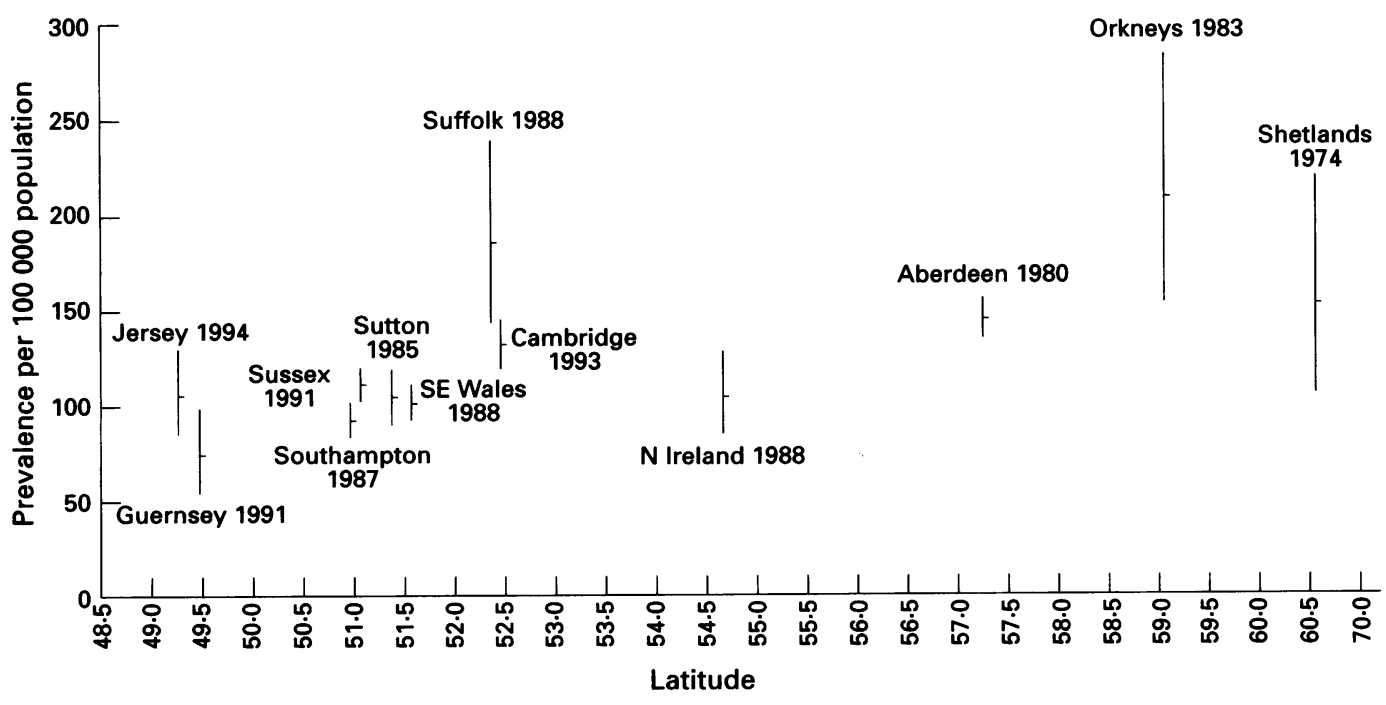

Latitudinal gradient in contemporary United Kingdom studies on prevalence of multiple sclerosis. 


\begin{tabular}{|c|c|c|c|c|c|c|c|c|c|c|}
\hline \multicolumn{9}{|c|}{ Poser } & \multirow[b]{2}{*}{$S P R$} & \multirow[b]{2}{*}{$95 \% C I$} \\
\hline All & Pt No & $95 \% C I$ & $M S$ & $P_{t} N o$ & $95 \% C I$ & Susp & Pt No & $95 \% C I$ & & \\
\hline - & - & - & - & - & - & - & - & - & - & - \\
\hline - & - & - & - & - & - & - & - & - & - & - \\
\hline- & - & - & - & - & - & - & - & - & - & - \\
\hline - & - & - & - & - & - & - & - & - & - & - \\
\hline - & - & - & - & - & - & - & - & - & - & - \\
\hline - & - & - & - & - & - & - & - & - & - & - \\
\hline- & - & - & - & - & - & - & - & - & - & - \\
\hline- & - & - & - & - & - & - & - & - & - & - \\
\hline- & - & - & - & - & - & - & - & - & - & - \\
\hline- & - & - & - & - & - & - & - & - & 153 & $140-166$ \\
\hline- & - & - & - & - & - & - & - & - & $\overline{201}$ & $\overline{101}$ \\
\hline- & - & - & - & - & - & - & - & - & 221 & $184-261$ \\
\hline - & - & - & - & - & - & - & - & - & - & - \\
\hline- & - & - & - & - & - & - & - & - & - & - \\
\hline- & - & - & - & - & - & - & - & $\overline{-}$ & - & $\overline{126}$ \\
\hline $\begin{array}{l}117 \\
120\end{array}$ & $\begin{array}{l}441 \\
453\end{array}$ & $\begin{array}{l}107-129 \\
110-132\end{array}$ & $\begin{array}{l}101 \\
101\end{array}$ & $\begin{array}{l}380 \\
379\end{array}$ & $\begin{array}{l}91-112 \\
91-111\end{array}$ & $\begin{array}{l}16 \\
20\end{array}$ & $\begin{array}{l}60 \\
74\end{array}$ & $\begin{array}{l}12-21 \\
16-25\end{array}$ & 139 & $\begin{array}{l}126-150 \\
-\end{array}$ \\
\hline $\begin{array}{l}\overline{130} \\
152\end{array}$ & $\begin{array}{l}\overline{374} \\
441\end{array}$ & $\begin{array}{l}\overline{117-144} \\
138-167\end{array}$ & $\begin{array}{l}\overline{112} \\
131\end{array}$ & $\begin{array}{l}\overline{322} \\
380\end{array}$ & $\begin{array}{l}\overline{100}-125 \\
118-145\end{array}$ & $\begin{array}{l}\overline{19} \\
21\end{array}$ & $\begin{array}{l}\overline{54} \\
61\end{array}$ & $\begin{array}{l}\overline{14}-24 \\
16-27\end{array}$ & $\begin{array}{l}\overline{121} \\
142\end{array}$ & $\begin{array}{l}\overline{108}-133 \\
129-157\end{array}$ \\
\hline- & - & - & - & - & - & - & - & - & 129 & $111-147$ \\
\hline 99 & 411 & 89-109 & 95 & 395 & 86-105 & 4 & 16 & $2-6$ & 115 & $104-127$ \\
\hline 136 & 810 & $127-145$ & 111 & 665 & $103-120$ & 24 & 145 & $21-29$ & - & - \\
\hline- & - & - & 100 & 84 & $81-124$ & - & - & - & 120 & $96-144$ \\
\hline - & - & - & 74 & 45 & $55-99$ & - & - & - & 96 & $70-121$ \\
\hline
\end{tabular}

inconsistency and we have assumed the total number of cases as 412 (probable $=384$; early and possible $=28$ ) and not 411 as published. ${ }^{11}$ Minor corrections are also included for other surveys based on recalculations of the prevalence figures. The most recent prevalences for Orkney differ from the published figures ${ }^{23}$ because, in line with the general principles for estimating prevalence, we have included the three cases with definite or probable disease living on the islands in 1983 but with onset elsewhere. Although the standardised prevalence ratios provide the best comparator between surveys, hitherto these have used the Allison and Millar criteria with adjustment to the population denominator of Northern Ireland in 1951. Thus the prevalence ratio published in this issue by Rice-Oxley et $a l^{15}$ for Sussex (100/105; CI 92-108) is based on definite and probable cases classified using the Poser criteria without standardisation to a reference population. In situations where the total number of cases (definite, probable, and suspected-Poser; probable, early, and possible-Allison and Millar) is identical using either classification (south east Wales, ${ }^{89}$ Southampton, ${ }^{11}$ and Cambridgeshire), this will not matter; but the pronounced differences which emerge with the restriction of cases to the definite/probable or probable/early categories are well illustrated by the 19 cases who appear in the Channel Islands survey using the Allison and Millar criteria but are unclassifiable under the Poser scheme. Furthermore, there is inconsistency of approach, using either system, to the isolated demyelinating episode with symptomatic recovery and no recurrence at the same or another site. This is apparent in the paper by Rice-Oxley et al, ${ }^{15}$ who omit 40 such cases using the Allison and Millar criteria which others might well have included, over and above the 52 with persistent spinal cord syndromes featured as having possible multiple sclerosis. A superficial assessment of the prevalences for southern parts of the British Isles published between 1985 and 1990, and with classification using the Poser criteria, seems to show a lower figure for Southampton than elsewhere; however, when the figures for definite and probable multiple sclerosis only, or the standardised prevalence ratios, are compared, this difference is lost indicating the extent to which the inclusion of suspected cases introduces noise, and generally obfuscates the overall picture.
For the future, it is clear that more consistency of approach is needed. To some extent this can be achieved by agreeing ground rules for diagnostic criteria, deciding on the inclusion or omission of suspected cases, and through insistence on the quotation of confidence intervals and the use of standardised prevalence ratios. Less easy is the adoption of a population for standardisation that is appropriate for surveys being conducted throughout the world and involving peoples of different genetic background and demographic characteristics.

Can anything now be said about the distribution of multiple sclerosis in the United Kingdom? With the steady rise in prevalence for southern parts of England and the more stable rates in north east Scotland, there does seem to have been a reduction in slope of the previously demonstrated gradient in frequency. Without knowing the extent to which surveys of multiple sclerosis in north east Scotland have saturated prevalent cases, and with continuing uncertainty on whether other parts of the country have yet reached a steady state, it is difficult to predict how much further the gradient will collapse. The probability remains that the north east of Scotland genuinely has a higher frequency of multiple sclerosis than other parts of the United Kingdom; and if so, differences in features of the population at risk, correlating with genetic clines, still offer an attractive, but not exclusive, explanation. When the confounding effect of comparing repeatedly surveyed regions with virgin territories, and the wide confidence intervals for many of the studies based on small denominators, are taken into account, the evidence for a systematic change in prevalence of multiple sclerosis with latitude in the United Kingdom now seems less secure.

NEIL ROBERTSON ALASTAIR COMPSTON University of Cambridge Neurology unit, Addenbrooke's Hospital,
Hills Road, Cambridge CB2 $2 Q Q$ UK

Correspondence to: Professor D A S Compston

1 Limburg CC. The geographic distribution of multiple sclerosis and its estimated prevalence in the United States. Association for Research in Nervous and Mental Diseases 1950;28:15-24.

2 Kurtzke JF. Epidemiologic evidence for multiple sclerosis as an infection. Clin Microbiol Rev 1993;6:382-427.

3 Compston DAS, Ebers GC. The genetics of multiple sclerosis. In: Cook SD, ed. Handbook of neurology. New York: Decker, 1990:25-39.

4 Compston DAS. The dissemination of multiple sclerosis. $\dot{f} R$ Coll Physicians Lond 1990;24:207-18. 
5 Compston DAS. Risk factors for multiple sclerosis: race or place? $\mathcal{f}$ Neurol Neurosurg Psychiatry 1990;53:821-3.

6 Swingler RJ, Compston DAS. The distribution of multiple sclerosis in the United Kingdom. $\Im$ Neurol Neurosurg Psychiatry 1986;49:1115-24.

7 Williams ES, Jones DR, McKeran RO. Mortality rates for multiple sclerosis: geographical and temporal variations revisted. $f$ Neurol Sclerosis: geographical and tempo

8 Swingler RJ, Compston DAS. The prevalence of multiple sclerosis in south east Wales. F Neurol Neurosurg Psychiatry 1988;51:1520-4.

9 Hennessy A, Swingler RJ, Compston DAS. The incidence and mortality of multiple sclerosis in south east Wales. $\mathcal{f}$ Neurol Neurosurg Psychiatry 1989;52:1085-9.

10 Williams ES, McKerron RO. Prevalence of multiple sclerosis in a South London borough. BMF 1986;293:237-9.

11 Roberts MHW, Martin JP, McLelland L, MacKintosh-Michaelis SA, Spackman AJ. The prevalence of multiple sclerosis in the Southampton South West Hampshire Health Authority. F Neurol Neurosurg Psychiatry 1991;54:55-9.

12 Phadke JG, Downie AW. Epidemiology of multiple sclerosis in the North East (Grampian Region) of Scotland-an update. $\mathcal{f}$ Epidemiol Community Health 1987;41:5-13.

13 Mumford CJ, Fraser MB, Wood NW, Compston DAS. Multiple sclerosis in the Cambridge health district of East Anglia. $f$ Neurol Neurosurg Psychiatry 1992;55:887-2.

14 Lockyer MJ. Prevalence of multiple sclerosis in five rural Suffolk practices. $B M \mathcal{F} 1991 ; 303: 347-8$.

15 Rice-Oxley M, Rees JR. A prevalent survey of multiple sclerosis in Sussex. f Neurol Neurosurg Psychiatry 1995;58:27-30.

16 Sharpe G, Price SE, Last A, Thompson RJ. Multiple sclerosis in island populations-prevalence in the Bailiwicks of Guernsey and Jersey. f Neurol Neurosurg Psychiatry 1995;58:22-6.

17 Sutherland JM. Observations on the prevalence of multiple sclerosis in northern Scotland. Brain 1956;79:635-54.

18 Shepherd DI, Downie AW. Prevalence of multiple sclerosis in north east Scotland. BMF 1978;II:314-6.

19 Shepherd DI, Downie AW. A further prevalence study of multiple sclerosis in north east Scotland. F Neurol Neurosurg Psychiatry 1980; 43:310-5.

20 Downie AW. The Chief Scientist Report. . . multiple sclerosis in north east Scotland. Health Bulletin (Edinburgh) 1984;42:151-6.

21 Allison RS. Some neurologic aspects of medical geography. Proc $R$ Soc Med 1963;56:71-6.

22 Fog T, Hyllested K. Prevalence of disseminated sclerosis in the Faroes, the Orkneys, and Shetland. Acta Neurologica Scandinavica 1966;42 (suppl 19):9-11.
23 Poskanzer DC, Prenney LB, Sheridan JL, Condy JW. Multiple sclerosis in the Orkney and Shetland Islands. 1: Epidemiology, clinical factors in the Orkey and Shetand Islands. 1: Epidemiology, clinical fact

24 Cook SD, Cromarty J, Tapp W, Poskanzer D, Walker JD, Dowling PC. Declining incidence of multiple sclerosis in the Orkney Islands. Declining incidence of

25 Kurtzke JF. Multiple sclerosis: changing times. Neuroepidemiology 1991; 10:1-8.

26 Gronning M, Riise T, Kvale G, Nyland H, Larsen JP, Aarli JA. Incidence of multiple sclerosis in Hordaland, western Norway: a fluctuating pattern. Neuroepidemiology 1991;10:53-61.

27 Svenningsson A, Runmarker B, Lycke J, Andersen O. Incidence of MS during two fifteen-year periods in the Gothenburg region of Sweden. Acta Neurologica Scandinavica 1990;82:161-8.

28 Poser CM, Benedikz J, Hibberd PL. The epidemiology of multiple sclerosis: the Iceland model. Onset-adjusted prevalence rate and other methodological considerations. I Neurol Sciences 1992;111:143-52.

29 Allison RS, Millar JHD. Prevalence and familial incidence of disseminated sclerosis. Ulster Med f 1954;(suppl 2):92.

30 Poser CM, Paty DW, Scheinberg L, McDonald WI, Davies FA, Ebers GC, et al. New diagnostic criteria for multiple sclerosis: guidelines for research protocols. Ann Neurol 1983;13:227-31.

31 Millar JHD, Allison RS. Multiple sclerosis, a disease acquired in childhood. Springfield: CC Thomas. 1971:98.

32 Hawkins SA, Kee F. Updated epidemiological studies of multiple sclerosis in northern Ireland. 7 Neurol 1988;235(suppl):S86.

33 Dean G, Goodall J, Downie A. The prevalence of multiple sclerosis in the Outer Hebrides compared with north-east Scotland and the Orkney and Shetland Islands. $\mathcal{f}$ Epidemiol Comm Health 1981;35:110-3.

34 Poskanzer DC, Schapira K, Miller H. Epidemiology of multiple sclerosis in the counties of Northumberland and Durham. $\mathcal{F}$ Neurol Neurosurg Psychiatry 1963;26:368-76.

35 Brewis M, Poskanzer DC, Rolland C, Miller H. Neurological disease in an English city. Acta Neurologica Scandinavica 1966;42(suppl 24):1-89.

36 McCoubrie $M$, Shuttleworth $D$. The prevalence of multiple sclerosis in west Yorkshire. BMF 1978;2:570.

37 Campbell AMG, Herdang G, Tatlow WFT, Whittle EG. Lead in relation to multiple sclerosis. Brain 1950;73:52-71.

38 Hargreaves ER. Epidemiological studies in Cornwall. Proc $R$ Soc Med 1969;54:209-16.

39 Elian M, Dean G, Nightingale S. Multiple sclerosis among United Kingdom born children of immigrants from the Indian subcontinent, Africa, and the West Indies. $F$ Neurol Neurosurg Psychiatry 1990;53 906-11.

\section{Neurological stamp}

\section{Mistletoe}

The mistletoe was worshipped by the Druids. It seemed to defy nature by living its entire life aloft in the branches of trees, never descending to the earth, which seemed to be a plant's natural habitat. In former times it was surrounded by an aura of awe as the key to the supernatural.

For centuries the mistletoe had a therapeutic reputation and its medicinal virtues have included its use as a sedative, treatment for epilepsy, headache, paralysis, hypertension, lung ailments, and debility. A sprig of mistletoe was the "golden bough" of the famous Trojan hero Aeneas. When Aeneas visited the underworld, the prophetess Sibyl bade him arm himself with the golden bough and together they descended to the "Land of Shades".

The mistletoe is shown on a Christmas stamp issued by Guernsey in 1978 (Stanley Gibbons 176, Scott 172). The display of the mistletoe at Christmas and New Year dates back to a Norse tradition.

L F HAAS

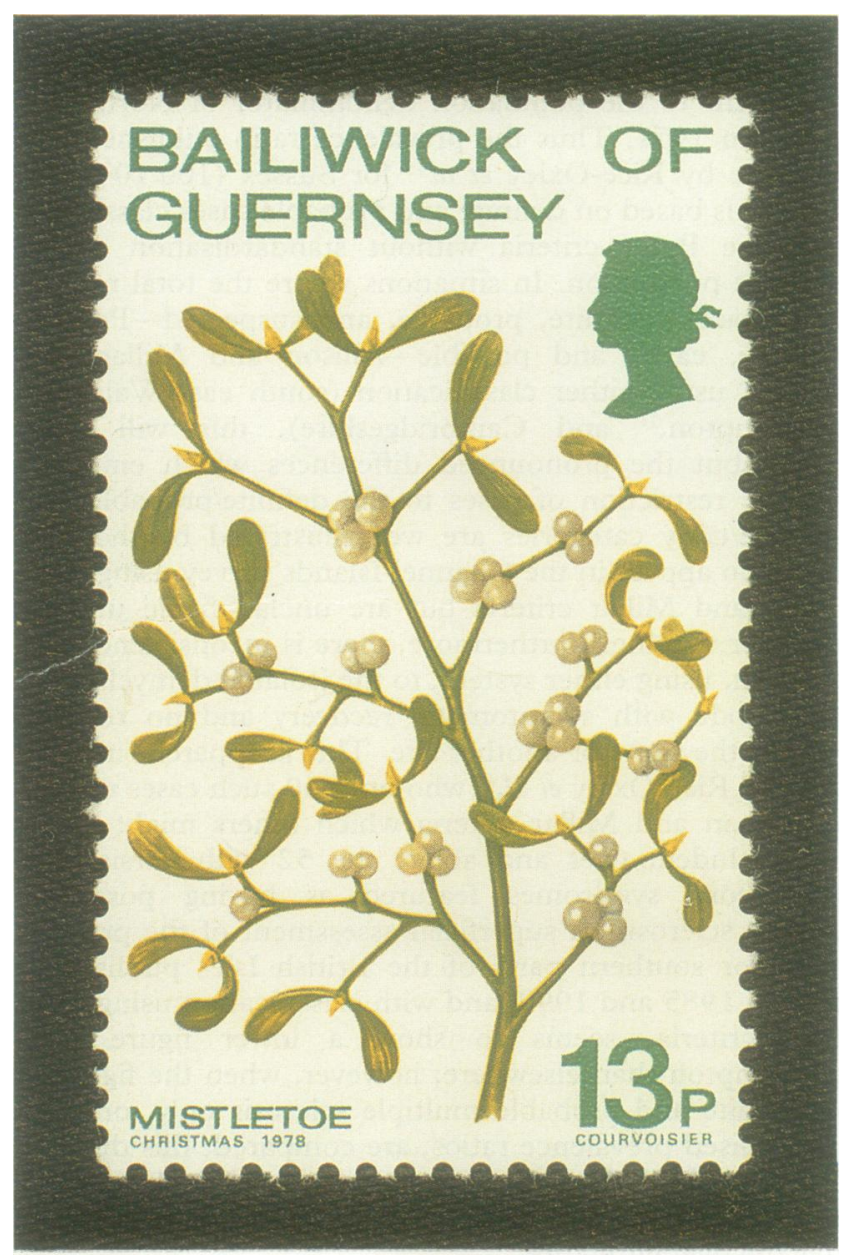

